\title{
DETERMINATION OF AFLATOXIN M1 IN RAW COW'S MILK BY USING HPLC- FLD, IN INJIBARA TOWN, AWI ZONE, AMHARA, ETHIOPIA
}

\author{
Adisie Kassa $^{1 *}$, Alemu Talema ${ }^{1}$, Getasew Ketsela \\ Corresponding Author: adiskassa12@gmail.com \\ Co-author: alemu212121@gmail.com \\ ${ }^{1}$ Department of Chemistry, College of Natural and Computational Sciences, Injibara University \\ P. O. Box. 40, Injibara, Ethiopia
}




\begin{abstract}
The aim of this study, therefore, provides information about Aflatoxin levels in raw cow's milk in Injibara Town of Awi Administrative zone by using HPLC-FLD. A good linearity of standard calibration was found for AFM1 at a range of 0.5-7 $\mu \mathrm{g} / \mathrm{L}$. Regression coefficient $\left(\mathrm{R}^{2}\right)$ values were 0.9999 , whereas slope and intercept were 2.5278 and 0.1012 , respectively. The average recoveries for the spiked samples were range from76.62- $90.98 \%$ and the RSD values ranged between $2.55-7.36 \%$. The results showed that $15 \%$ of samples ( 3 out of 20 ) were contaminated with AFM1 in the range of $0.046-0.22 \mu \mathrm{g} / \mathrm{L}$. The average contamination level was $0.121 \mu \mathrm{g} / \mathrm{L}$. The determined mean values of AFM1 in the collected milk samples were above the standard limit of the European Commission and lower than the level established by United States regulations. Further monitoring of Aflatoxin in milk samples from different regions of the country is justified to conclusively determine the actual safe/risks and possibly low Aflatoxinsrisk milk production areas.
\end{abstract}

Keywords: Ethiopia, Milk, Aflatoxin, Awi zone, HPLC-FLD, Aspergillus 


\section{Introduction}

Generally, nutrition that found highly in the human body is milk and its products. In developed countries like Europe, the amount of milk and its products consumed per day is approximately $340 \mathrm{~g}$ /day per person [1]. Milk can be used in all stages of human beings, especially for mothers, children, old people, and infants and it is the basic dietary for human beings $[2,3]$. From the different types of mycotoxins, Aflatoxin is the main one which mainly found in milk that generated from the animal feed by the toxigenic materials mainly by fungi such as Aspergillus flavus, Aspergillus parasiticus and the rare Aspergillus nomius [4]. Generally, the word of "Aflatoxin" is derived from the three words; one is "a" from the Aspergillus genus and the other is "fla" from the species flavus and the other third is from toxin which means poison. Different scholars stated that ingestion is the main root of Aflatoxin species for living things, especially for humans and animals through the feeding channel [5]. From the different types of Aflatoxins, such as AFB1, AFB2, AFG1, AFG2, AFB1 and AFM2, Aflatoxin M1 (AFM1) is the most common [6].

The bloodstream contains the byproduct of the metabolisms and in the bile or urine which is excreted, as well as mainly, Aflatoxin M1released in milk and eggs [7, 8]. Some of the Aflatoxin is metabolized to the Aflatoxin M1 in the cattle when they ingested the Aflatoxin B1 and which is found and excreted in the milk. Aflatoxin (M1) can be found in the milk product such as cheese and yogurt because of this Aflatoxin is thermally stable in the process of pasteurization/thermal treatments of milk [7,9]. In the case of parts of milk, Aflatoxin M1 is strongly attached due to the production of this Aflatoxin M1 during the process of the technological generation of cheese. Several parameters that determine the contents of Aflatoxin M1 in the milk and from these factors, some of them are the breeding system of animals, period of location, infections of mammary, etc. After a cattle is ingested the AFB1, AFM1 is within one (12-24 hrs) detected and within a short period, it can reach a high level. The aim of this study, therefore, will provide information about Aflatoxin levels in raw cow's milk in Injibara Town of Awi Administrative zone by using HPLC-FLD method detection. 


\section{Methodology and Materials}

\subsection{Description of the study site}

Amhara is one of the regional states of Ethiopia in which located between $8^{\circ} 45^{\prime} \mathrm{N}$ and $13^{\circ} 45^{\prime} \mathrm{N}$ latitude and $35^{\circ} 46^{\prime} \mathrm{E}$ and $40^{\circ} 25^{\prime} \mathrm{E}$ longitude in North West Ethiopia. The climate of the Amhara Region is affected significantly by variation in altitude, latitudinal position, prevailing winds, air pressure and circulation and its proximity to the sea [10]. The study was conducted in Injibara Town of Awi zone; one zone of Amhara regional state. The study was conducted from February to August, 2018/2019. Awi is the one among the 11 zone of the Amhara regional state. The highest and lowest altitude of Injibara is recorded to be 2540 m.a.s.1 and 3000 m.a.s.1 respectively. According to the town's Administration, the total area of the town is estimated to be $28.3 \mathrm{~km}$. It was divided into 5 urban Kebeles under the town administration. According to the development plan of Injibara, social and personal services are the dominant sector in the town's economy followed by trade (especially charcoal trade), tourism and Manufacturing dominating sector providing employment.

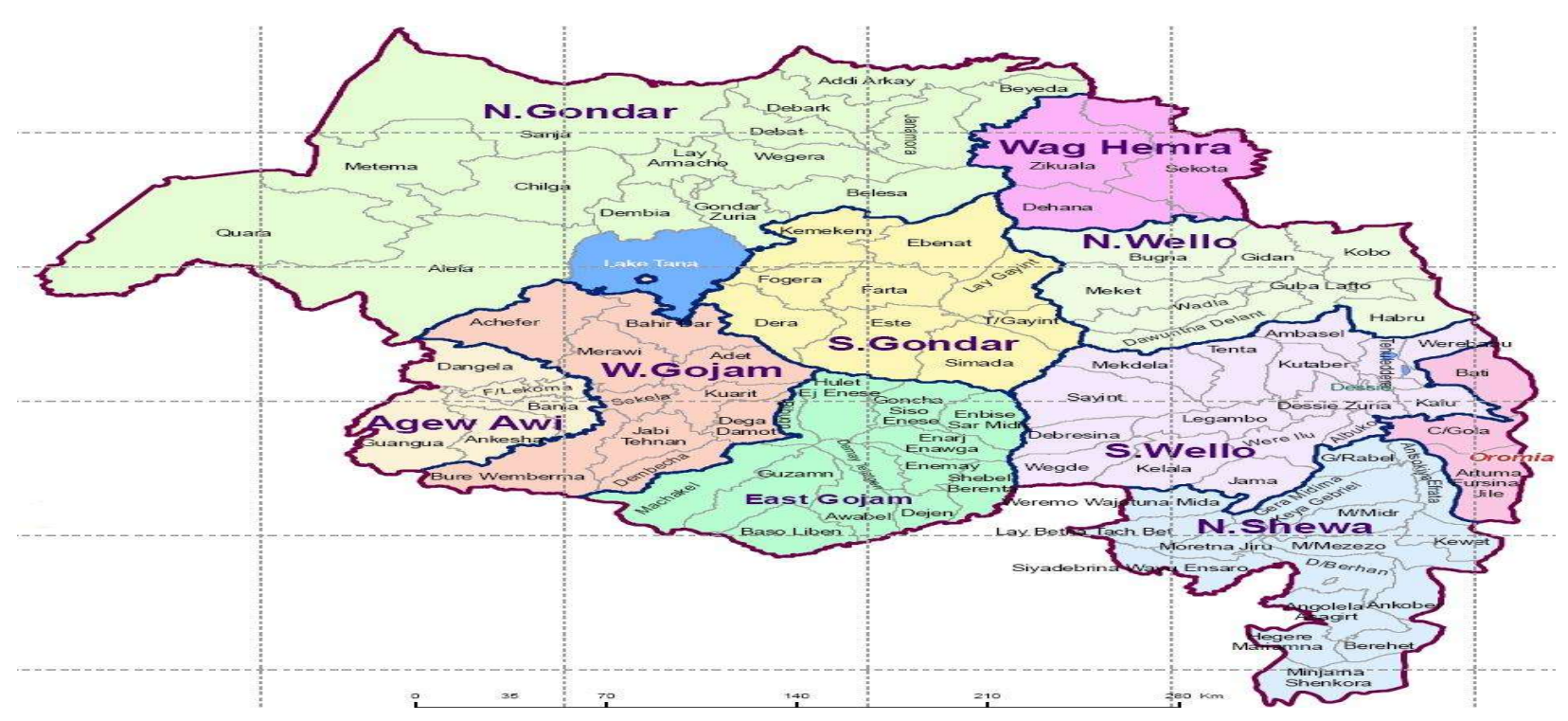

Figure 1: Map of study area

\subsection{Sampling method and sample collection}

A total of 20 raw cow's milk (500 mL each) samples were collected from individual farmers at Injibara Town of Awi Zone. Each sample was collected at night and morning during the day, through a systematic random sampling method and the collected raw cow's milk samples were 
placed in a clear polyethylene bag. The raw caw's milk was kept on the ice during the transportation and the collected sample was stored at $-18{ }^{\circ} \mathrm{C}$ in the refrigerator at Laboratory until the analysis.

\subsection{Apparatus and Instruments}

The following equipment was used in this study: electronic analytical balance was used for weighing standard, fast flow filter paper and funnel was used to filter the milk samples, micropipettes $(100,250,500,1000 \mathrm{~mL})$ were used for measuring volume of standard solutions, volumetric flasks $(50,100,250,500,1000 \mathrm{~mL})$ were also used for preparing working standard solutions and stock solutions, $2 \mathrm{~mL}$ autosampler vial with cap was used for stored the sample until analysis in HPLC-FLD, Nitrogen gas (purity > 99.8 \%) was used for evaporated the filtrate, Syringe filters $0.45 \mu \mathrm{m}$ used for sample filtration after filter paper, Immune-affinity column used to separate Aflatoxins M1 from the mixture of solution, chromatographic Eclipsed plus column C18 length of $100 \mathrm{~mm}$ internal diameter $4.6 \mathrm{~mm}$, particle diameter of packing material $5 \mu \mathrm{m}$ and HPLC equipped with FLD capable of providing about $365 \mathrm{~nm}$ excitation and $435 \mathrm{~nm}$ emission $\lambda$ were used to analysis Aflatoxins M1 in milk samples.

\subsection{Chemicals and Reagents}

Deionized water (conductivity $<0.06 \mu \mathrm{s} / \mathrm{cm}$ ), Acetone (purity $>99.8 \%$ ), HPLC grade methanol and Acetonitrile were used to prepare for mobile phase.

\subsection{Experimental Procedures}

The procedure used for AFM1 extraction and clean-up was based on the instructions described by Ethiopian confirmative assessment enterprise agency (ECAE) for AFM1 determination in milk: Mobile phase was prepared from De-ionized water: acetonitrile: methanol (60:25:15) by mix accurately in $1000 \mathrm{~mL}$ volumetric flask. Aflatoxin M1 stock solutions (5 mg/L) were prepared by dissolves $25 \mu \mathrm{g}$ Aflatoxin M1 standard solid in $5 \mathrm{~mL}$ methanol. Then, $0.5 \mathrm{mg} / \mathrm{L}$ and $0.01 \mathrm{mg} / \mathrm{L}$ Aflatoxin M1 intermediate solutions were prepared from $5 \mathrm{mg} / \mathrm{L}(1 \mathrm{~mL})$ and $0.5 \mathrm{mg} / \mathrm{L}$ $(0.2 \mathrm{~mL})$ by using mixture of water: acetonitrile: methanol (60:25:15) in $10 \mathrm{ml}$ of volumetric flask. Calibration curves were based on the analysis of working standard solutions $0.5,1,2,4,5$ and $7 \mu \mathrm{g} / \mathrm{L}$ by the mobile phase. 


\subsection{Preparation of milk sample and Extraction}

The freeze samples were warmed in a water bath with $37{ }^{\circ} \mathrm{C}$ for $30 \mathrm{~min}$ and $25 \mathrm{~mL}$ of prepared sample was added into a $50 \mathrm{ml}$ falcon tube and it was centrifuge with $2000 \mathrm{~g}$ for $5 \mathrm{~min}$. Then the solution was filtered by fast flow (541) filter paper that attached with the immune-affinity column and the filtrate was passed in the immune-affinity column with $1 \mathrm{drop} / \mathrm{sec}$. Then the immune-affinity column was washed with $5 \mathrm{ml}$ of $10 \mathrm{mM}$ PBS three times and dries by passing air through it. Aflatoxin M1 was eluted with $1 \mathrm{~mL}$ of methanol three times and filter through $0.45 \mu \mathrm{m}$ syringe filter into amber auto-sampler and transfer to $2 \mathrm{~mL}$ vial for HPLC analysis.

\subsection{Method Validation}

The proposed method was validated by evaluating different parameters as a limit of detection (LOD), limit of quantitation (LOQ), accuracy (in terms of recovery) and precision (in terms of repeatability) [11].

\subsubsection{Limit of Detection}

Limit of detection (LOD) is the minimum concentration of analyte that can be detected but not necessarily quantified with acceptable uncertainty. Limit of detection for each Aflatoxin M1 was determined from an analysis of three replicates of method blanks [12]. LOD was calculated as:

$\mathrm{LOD}=3 \times \mathrm{Sb}_{1}$.

Where, $\mathrm{Sb}_{1}$ is the standard deviation of the method blank.

\subsubsection{Limit of Quantification}

Limit of quantification (LOQ) is the lowest concentration of analyte that can be determined with an acceptable level of uncertainty. Limit of quantification was obtained from an analysis of three replicate of method blanks. The limit of quantification was calculated as ten times the standard deviation of the blank.

$\mathrm{LOQ}=10 \times \mathrm{Sb}_{1}$

Where, $\mathrm{Sb}_{1}$ is the standard deviation of the method blank [12].

\subsubsection{Precision and Accuracy}

Precision is the extent of the consistency of results as they are obtained during repeated applications a specified determination method. It was evaluated regarding repeatability by estimating the relative standard deviation (RSD) of the recovery percentage for each spiked 
level. Accuracy was evaluated through recovery studies of sample spikes. Triplicate samples were prepared and triplicate readings were obtained. The relative standard deviations of the sample were obtained as:

$\operatorname{RSD}(\%)=\frac{\text { Standard deviatio }}{\text { Mean vaue }} 100$

The percentage recoveries of the analyte were calculated to evaluate the accuracy of the analytical procedure. Recovery was then calculated as:

Recovery $(\%)=\frac{\text { Conc.in spiked sample }- \text { Conc.in unspiked sample }}{\text { Amount added }} \times 100$

\subsection{HPLC-FLD Analysis Condition}

The Mobile phase was the mixture of $60 \%$ deionized water: $25 \%$ acetonitrile: $15 \%$ methanol and the injection volume and the flow rate of HPLC-FLD were $20 \mu \mathrm{L}$. and $0.5 \mathrm{~mL} / \mathrm{min}$ respectively and column temperature $35^{\circ} \mathrm{C}$ as well as the run time 8 min and column type eclipsed plus C18 4.6 mm*100 mm*3.5 $\mu \mathrm{m}$. The HPLC-FLD Excitation and Emission was 365 and $435 \mathrm{~nm}$, respectively.

\subsection{Statistical analysis}

All statistical analyses were done by the Microsoft Office Excel-2010 program. Data expressed as mean \pm standard deviation (SD) of three replicate experiments for recovery. 


\section{Results and discussions}

\subsection{Calibration curve}

For the present study, standard solutions were used for preparing the intermediate solution and then working standard solutions were prepared from the intermediate solution of AFM1. The calibration curve was plotted with six points for each standard using peak area against concentrations and the calibration curve is given in Figure 2. Linearity of HPLC-FLD system was done by injecting different concentrations of standard and the system was calibrated by using the working solutions of Aflatoxin M1 in the range of $0.5-7 \mu \mathrm{g} / \mathrm{L}$ and the response (peak area) is given in Table $\mathbf{1}$.

Table 1: The series working standard solutions of Aflatoxin and responses

\begin{tabular}{|l|l|l|l|l|l|l|}
\hline Standard $(\mu \mathrm{g} / \mathrm{L})$ of AFM1 & 0.5 & 1 & 2 & 4 & 5 & 7 \\
\hline peak area & 1.3 & 2.6 & 5.2 & 10.3 & 12.8 & 17.7 \\
\hline
\end{tabular}

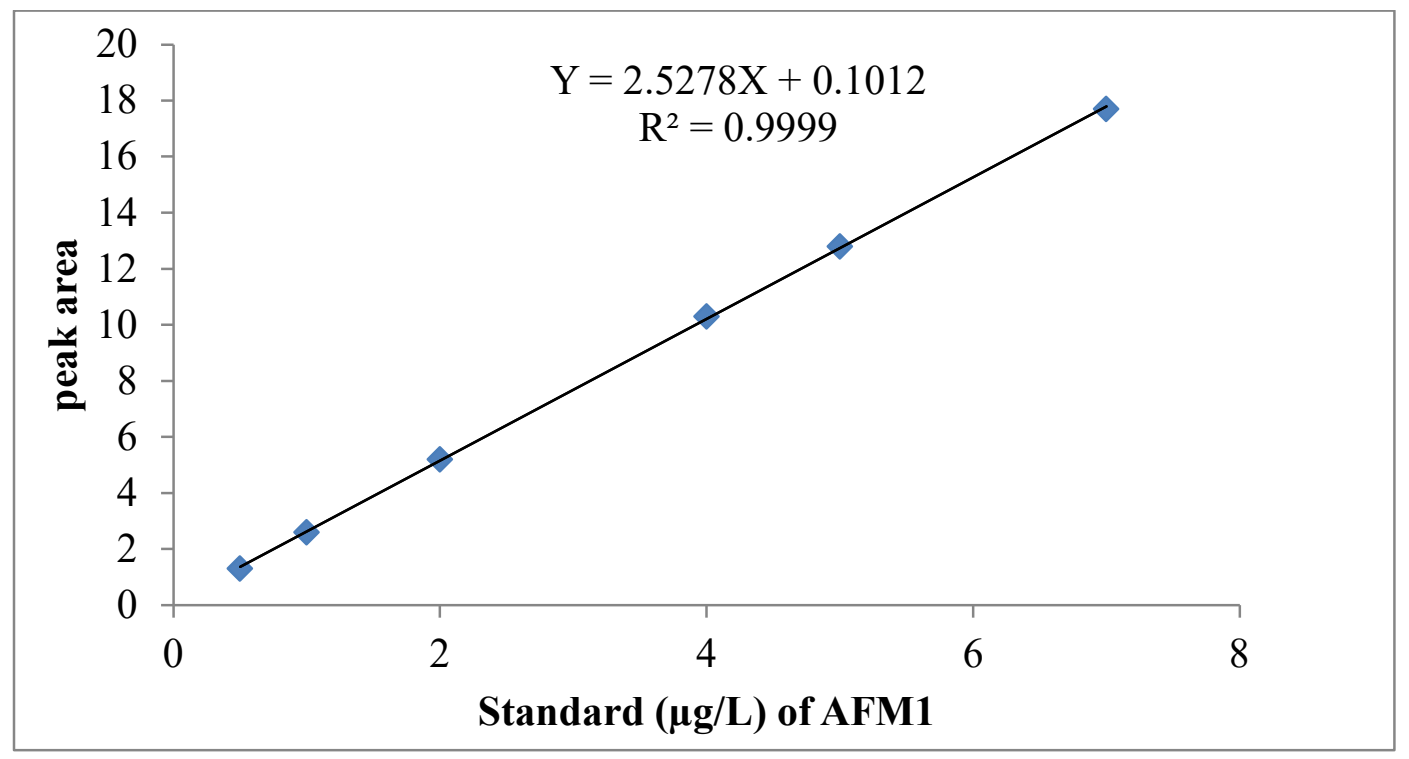

Figure 2: Calibration curve of standard AFM1

The calibration curve of AFM1 was constructed by using the peak-area of the AFM1 versus the concentration of the working standard solution as the Figure 2. The method was linear for AFM1 from 0.5 to $7 \mu \mathrm{g} / \mathrm{L}$. From the Figure 2, the equation describing the calibration curve was: $\mathrm{Y}=2.5278 \mathrm{X}+0.1012$; where $\mathrm{Y}$ is the peak area and $\mathrm{X}$ is the concentration of AFM1 $(\mu \mathrm{g} / \mathrm{L})$. 
The analyzed working solution gives excellent values of the regression coefficient for Aflatoxin M1. A regression coefficient $\left(\mathrm{R}^{2}\right)$ value was 0.9999 which considered as evidence of an acceptable fit of the data to the regression line.

\subsection{Some method validation}

\subsubsection{Limit of Detection (LOD) and Limit of Quantification (LOQ)}

LOD and LOQ for Aflatoxin M1 were determined from the analysis of triplicate of method blanks. For the present study, three reagents blank solutions were taken for milk samples and each of the samples was analyzed for Aflatoxin M1 contents by HPLC-FLD instrument. The standard deviations for each element were calculated from blank measurements.

Table 2: Limit of detection (LOD) and limit of quantification (LOQ) of milk samples for the determination of Aflatoxin M1

\begin{tabular}{|l|l|l|}
\hline Parameters & LOD & LOD \\
\hline AFM1 & $0.045 \mathrm{ug} / \mathrm{L}$ & $1.35 \mathrm{ug} / \mathrm{L}$ \\
\hline
\end{tabular}

From Table 2, the limit of detection (LOD) and limit of quantification (LOQ) values for AFM1 analyzed in the milk samples were 0.045 and $1.35 \mathrm{ug} / \mathrm{L}$, respectively.

\subsubsection{Accuracy and Precision}

The results of accuracy and precision were evaluated through recovery tests. Accuracy of the method was determined by matrix spike recovery studies and precision was expressed as relative standard deviation (RSD) of triplicate results. In this study, the recovery test was done by spiking a suitable known quantity of Aflatoxin M1 standard solution into a test portion of the sample. The percentage recoveries of raw cow's milk samples were given in Table 3.

Table 3: Percentage recovery of Aflatoxin in raw cow's milk samples (mean $\pm \mathrm{SD}, \mathrm{n}=3$ )

\begin{tabular}{|l|l|l|l|}
\hline Sample code & Spiking level (ug/L) & Recovery mean \pm SD (\%) & RSD (\%) \\
\hline 23 & 0.2 & $76.62 \pm 5.64$ & 7.36 \\
\hline 25 & 0.2 & $77.79 \pm 4.57$ & 5.87 \\
\hline 28 & 0.4 & $90.98 \pm 2.28$ & 2.55 \\
\hline
\end{tabular}

$\mathrm{n}=$ triplicate analysis 
As can be seen from Table 3, the percentage recovery of the Aflatoxin M1 in the milk sample ranged between 76.62- 90.98 \% and the RSD values ranged between $2.55-7.36 \%$. Recoveries averaged at $76.62 \%($ range $=71.19-82.45 \%), 77.79 \%($ range $=75.15-83.06 \%)$ and $90.98 \%$ (range $=90.80-90.98 \%$ ) at concentrations of 0.2 and $0.4 \mathrm{ug} / \mathrm{L}$, respectively. The matrix spike recovery obtained in this study falls within the range of guidelines described by Association Officials of Analytical Chemistry (70 to $120 \%$ ), the acceptable range for a good recovery study. The high percentage recovery obtained from the study validates the accuracy of the method and the reliability of the levels of AFM1 concentration in this study. The RSD values of the samples were $<10 \%$, indicating that the proposed method was precise. The chromatogram of the spiked sample and standards are given in the appendixes $\mathbf{A}$ and $\mathbf{B}$.

\subsection{Determination of Aflatoxin M1 in raw cow' milk sample by HPLC-FLD}

In the present study, 20 raw cow's milk samples were collected from farmers of Injibara town and samples were analyzed in triplicate for AFM1 determination by HPLC-FLD. Aflatoxin M1 was detected in 3 out of 20 samples ( $15 \%$ of whole samples) quantities ranged from 0.046 to $0.22 \mathrm{ug} / \mathrm{L}$ and a mean value of $0.121 \mathrm{ug} / \mathrm{L}$ (Table 4) which was different from the average and range of AFM1 $(0.41 \mu \mathrm{g} / \mathrm{L}$ and $0.028-4.98 \mu \mathrm{g} / \mathrm{L})$ in milk samples reported in Ethiopia and the result of present study was found within the range of the previous results reported in Ethiopia [13]. From 20 raw cow's milk samples, two (10\%) were seen over and one sample (5\%) was below the permissible limits of EU and ES (0.05 ug/L). Although some of the samples were over the EU and ES permitted levels, but all of the milk samples under the analysis were below the standard limit of the USA $(0.5 \mu \mathrm{g} / \mathrm{L})$.

Table 4: Occurrence of AFM1 in raw milk samples analyzed by HPLC-FLD

\begin{tabular}{|l|l|l|l|l|l|l|}
\hline $\begin{array}{l}\text { Range } \\
(\mathrm{ug} / \mathrm{L}) \\
\text { AFM1 }\end{array}$ & $\begin{array}{l}\text { Free from } \\
\text { AFM1 } \\
(\mathrm{n} \& \%)\end{array}$ & $\begin{array}{l}\text { Contamination } \\
\text { of AFM1 } \\
(\mathrm{n} \& \%)\end{array}$ & $\begin{array}{l}\text { Mean } \\
(\mathrm{ug} / \mathrm{L})\end{array}$ & $\begin{array}{l}\text { EU standard } \\
(0.05 \mu \mathrm{g} / \mathrm{L}) \\
(\mathrm{n} \& \%)\end{array}$ & $\begin{array}{l}\text { USA standard } \\
(0.5 \mu \mathrm{g} / \mathrm{L}) \\
(\mathrm{n} \& \%)\end{array}$ & $\begin{array}{l}\text { Ethiopian standard } \\
(\mathrm{ES})(0.05 \mu \mathrm{g} / \mathrm{L}) \\
(\mathrm{n} \& \%)\end{array}$ \\
\hline$<0.046$ & $17(80)$ & $0(0)$ & - & - & - & - \\
\hline $0.046-0.22$ & $0(0)$ & $3(15)$ & 0.121 & $2(10)$ & $1(5)$ & $2(10)$ \\
\hline
\end{tabular}

In Table 4 summarizes, the number of samples analyzed and the number of samples found to contain detectable levels of AFM1 contamination in raw cow's milk. In this study that 2(10\%) of the examined raw milk samples from 20 samples were contaminated with Aflatoxin M1 and 
exceeded the European Union limit $(0.05 \mu \mathrm{g} / \mathrm{L})$. The variations in AFM1 levels among studies/sites could be associated with different reasons such as season, feeding systems, farm management practices, and analytical methods. It could also be linked to the carryover rate of AFB1 as AFM1 in milk which varies widely among animals, days and from one milking session to the next and it is greatly influenced by physiological factors such as diet and health status of animals [14]. The raw cow's milk was contaminated with AFM1 $(0.046,0.096$ and $0.22 \mu \mathrm{g} / \mathrm{L})$ in sample code 29, 34, 40 (the whole sample were coded the no. from 21 up to 40), respectively. The AFM1 level in milk samples has been investigated in several countries. Other literature reported the highest level of Aflatoxin contamination in milk samples collected from Bishoftu with a contamination level of $4.98 \mu \mathrm{g} / \mathrm{L}$ and the lowest was $0.028 \mu \mathrm{g} / \mathrm{L}$ from Addis Ababa [15]. Other studies from urban centers in Kenya have been reported AFM1 levels up to $0.68 \mu \mathrm{g} / \mathrm{L}$. In contrast to this result, the level of AFM1 contamination found in raw milk collected from Khartoum state in Sudan, with an average concentration of $2.07 \mu \mathrm{g} / \mathrm{L}$ and a maximum of $6.9 \mu \mathrm{g} / \mathrm{L}$ was higher than what was found in this study.

Table 5: Level of AFM1 in milk sample comparison with other countries

\begin{tabular}{|l|l|l|l|l|}
\hline \multirow{2}{*}{ Country } & \multicolumn{2}{|l|}{ AFM1 in milk $(\mu \mathrm{g} / \mathrm{L})$} & \multirow{2}{*}{ References } \\
\cline { 2 - 5 } & Mean & Range & Status & \\
\hline Ethiopia & 0.121 & $0.046-0.220$ & Medium & This study \\
\hline Ethiopia & 0.410 & $0.028-4.980$ & Medium & {$[13]$} \\
\hline Pakistan & 0.380 & $0.010-0.760$ & Medium & {$[16]$} \\
\hline India & 0.500 & - & Medium & {$[17]$} \\
\hline Iran & - & $0.0021-0.131$ & Low & {$[7]$} \\
\hline Egypt & 0.050 & - & Low & {$[18]$} \\
\hline
\end{tabular}

Low $=$ within the EU standard $(0.05 \mu \mathrm{g} / \mathrm{L}) ;$ Medium $=$ Within the USA standard $(0.5 \mu \mathrm{g} / \mathrm{L})$

The quality of milk in terms of Aflatoxin M1 contamination in this study was compared with other countries (Table 5) and the AFM1 contamination level was slightly higher than the AFM1 of milk studied in Egypt $(0.05 \mu \mathrm{g} / \mathrm{L})$ [18]. However, the quality of milk in terms of the level of AFM1 in milk was lower than the milk samples reported from India [15-17]. 
The difference of AFM1 in milk in Ethiopia, Egypt and Iran could be due to the difference in feed type used in Ethiopia which is mainly by-products wheat as compared to Ethiopia, Egypt and Iran mainly used by-products of maize and groundnut feeds that are the most susceptible commodities to Aflatoxin contamination as compared wheat [19,20]. It is interesting to note that the Aflatoxin level of milk in this study was in the " Medium" category (within the Stringent USA standard) similar to most reports from different countries, especially from India $[21,15,16]$ (Table 5).

The Chromatogram of tested samples is given below in Figure 3: Retention time (minutes) and peak area in $\mathrm{X}$ and $\mathrm{Y}$-axis values.

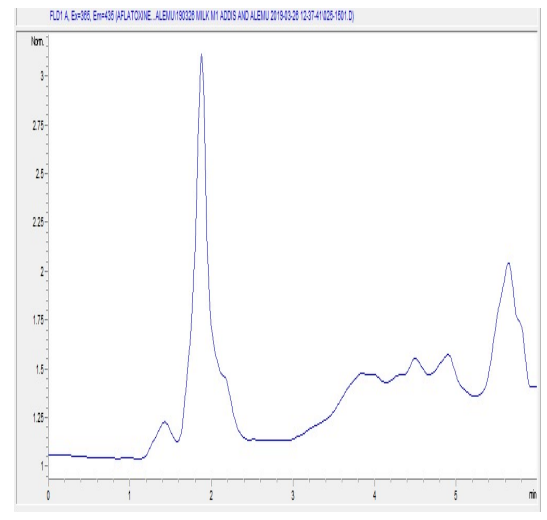

24

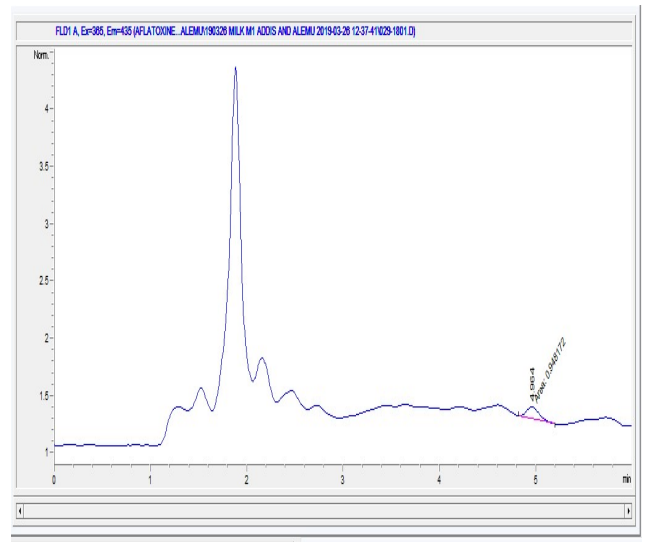

25

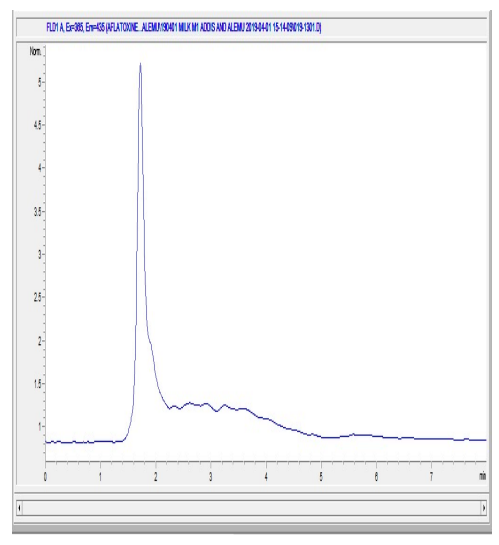

26

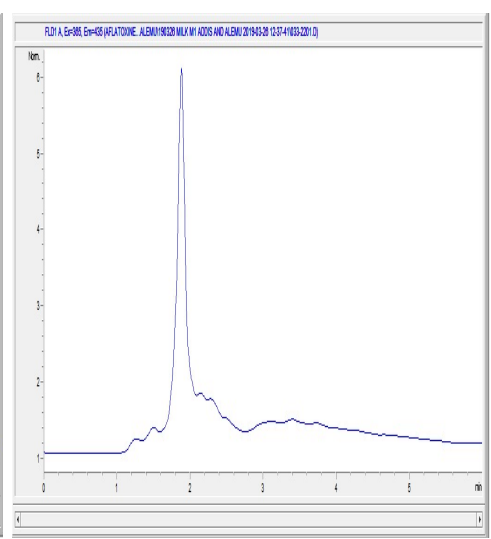




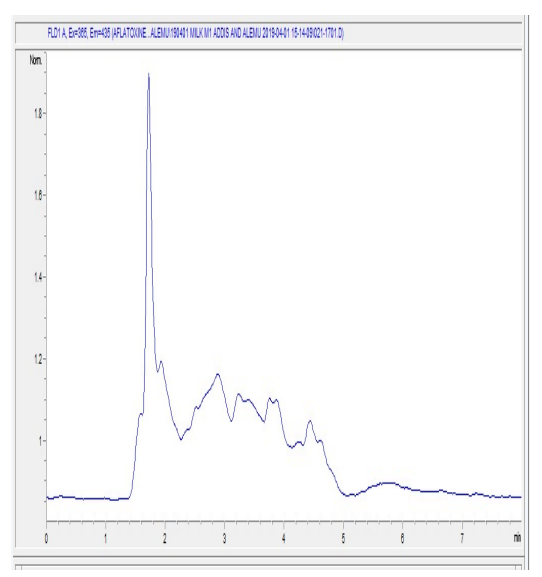

30

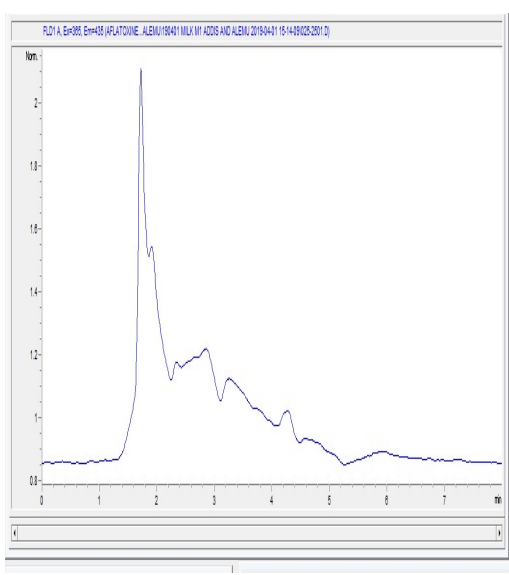

33

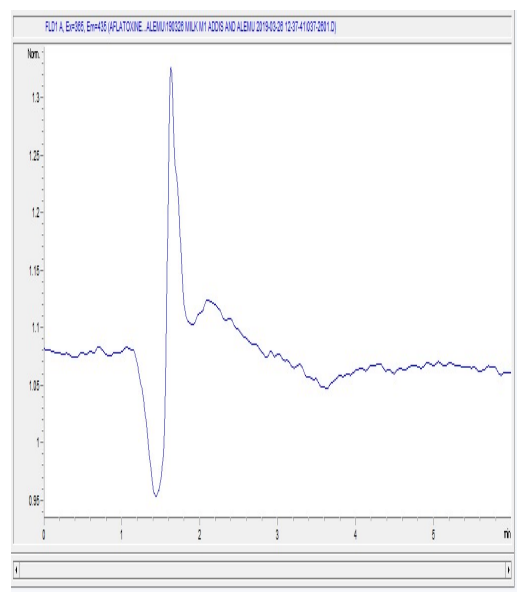

36

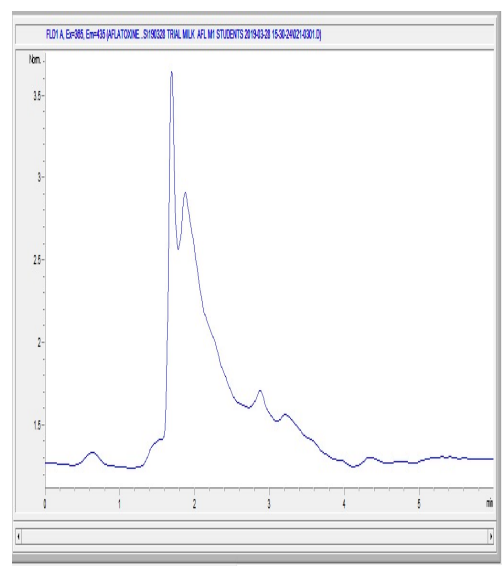

31

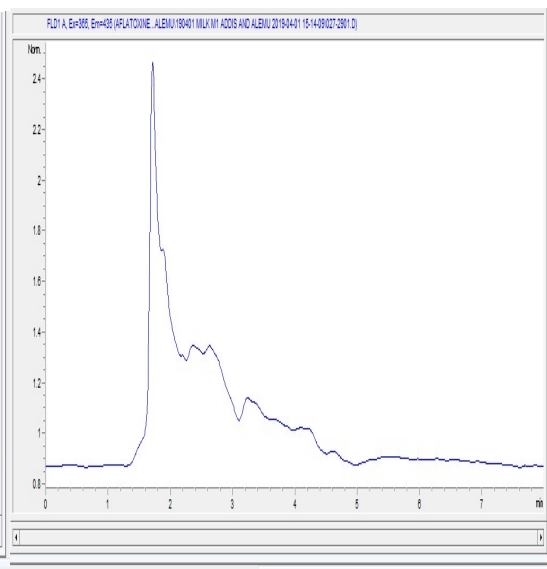

34

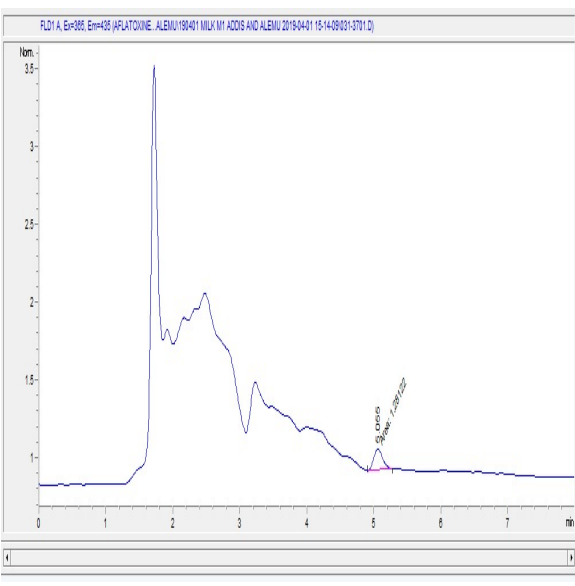

35
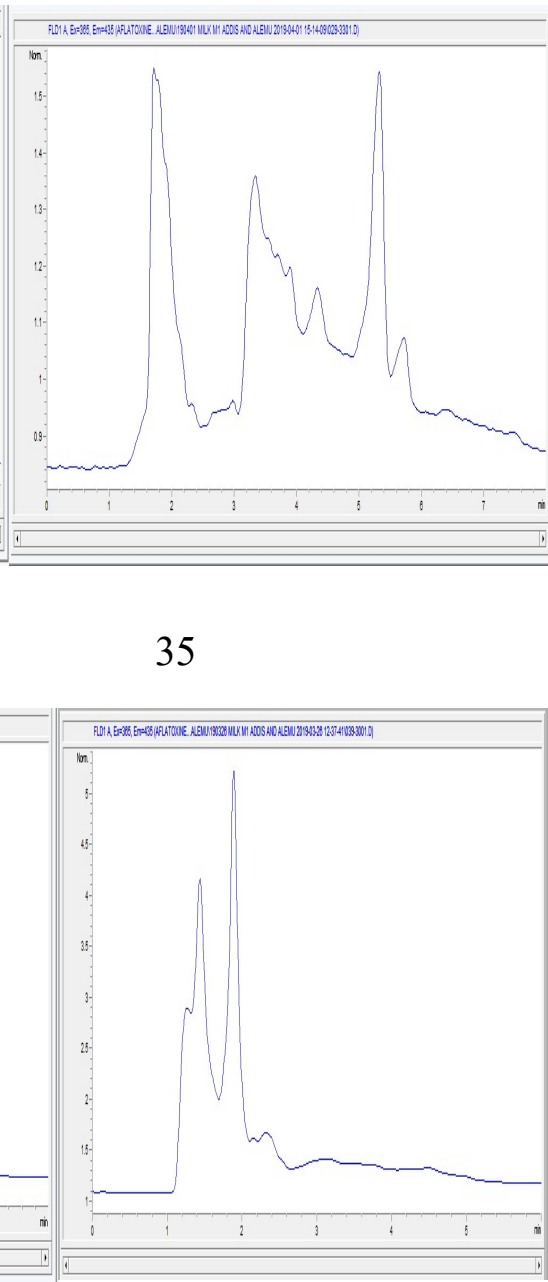


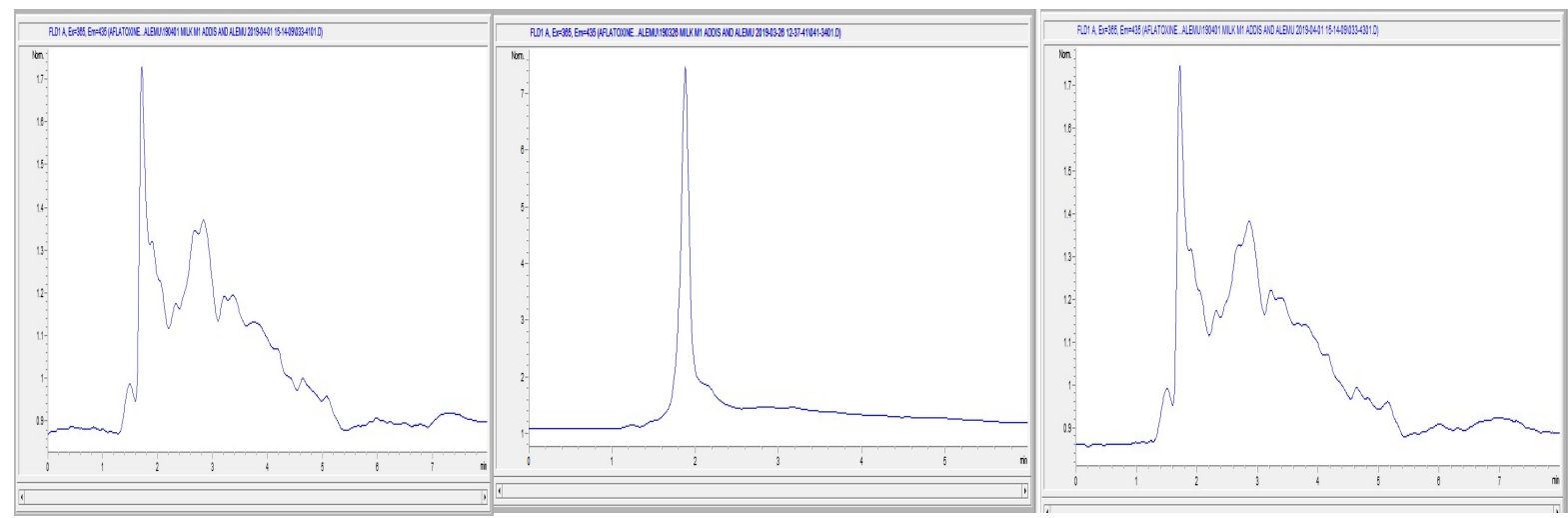

39

40

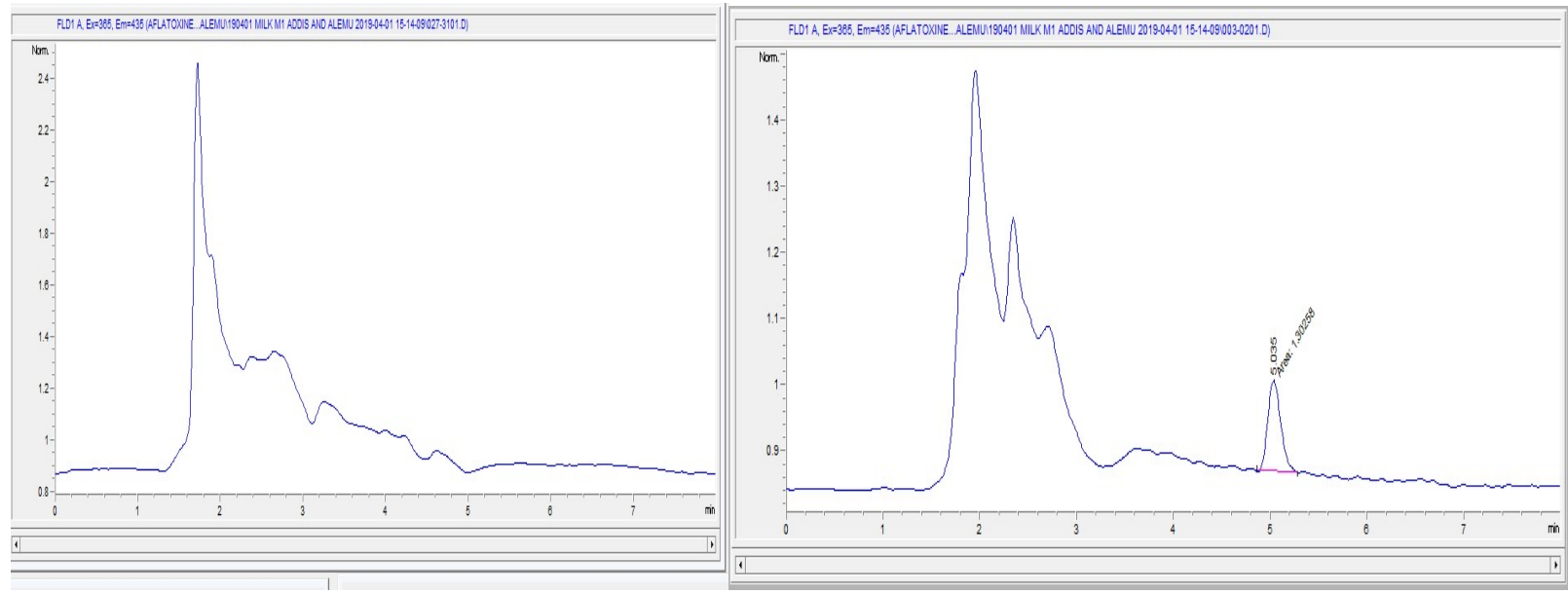

Figure 3: HPLC chromatogram of Aflatoxin M1 in the examined cow milk sample

From the Figure 3, the raw cow's milk was contaminated with AFM1 in sample 29 (0.046 $\mu \mathrm{g} / \mathrm{L})$, sample $34(0.096 \mu \mathrm{g} / \mathrm{L})$ and sample $40(0.22 \mu \mathrm{g} / \mathrm{L})$ and the levels of AFM1 in 17 milk samples from the 20 were no detected and no peaks were observed in the chromatogram except samples which represented by code 24 found below the LOD $(0.014 \mu \mathrm{g} / \mathrm{L})$. The retention time for AFM1 in this study was around 5 minutes in the chromatogram. The identification takes in consideration, if there is no peak at the characteristic retention time and the chromatogram is normal in all other aspects is assumed that the compound is not present and compound is present if the retention time of the compound in the test sample chromatogram coincides with the retention time of a standard compound in the reference chromatogram measured under the same conditions. 


\section{Conclusions and recommendations}

\subsection{Conclusion}

Milk is an essential source of nutrition and thus its consumption is increasing parallel to the continuous increase of the human population. Therefore, raw caw's milk has to be controlled continuously for the presence of AFM1 contamination. It is extremely important to maintain low levels of AFM1. Efficient control of AFM1 in milk requires efficient and easily performed analytical methods. According to results obtained in this study, seventeen(17) of the milk samples were no detected for Aflatoxin M1 contamination; whereas one sample below the detection limit and the remaining three from 20 samples were within the stringent USA level of $0.5 \mu \mathrm{g} / \mathrm{L}$. The AFM1 level of milk in this study was in the "Medium category" which was comparable to those AFM1 levels obtained elsewhere. It is important to prevent toxin production in feed, as well as create effective detoxification processes thus further studies are required to measure the level of AFM1 in the rations of supplementary feeds given to lactating cows concerning the level of AFM1 in milk.

Implementing a food supervision control system in the dairy products industries and application of strict regulations by the national government and other food control agencies, also frequent analytical surveillance are required to control the incidence of Aflatoxin in dairy products in Ethiopia. From the present study, one can observe that there is no more possibility of contaminant (Aflatoxin M1) in the milk sample of Injibara Town and it might be repeated with HPLC-MS to compare Aflatoxin M1contents of the selected sample types, as well as, we recommend further investigations on the contamination of milk by Aflatoxin M1 and their health implications on the people's feed.

Author Contributions: Alemu Talema contributed in methodology, writing original draft preparation, and project administration and Addise Kassa contributed in formal analysis, in supervision and software work.

Funding: This study was supported by fundamental research funds for the Injibara University, Ethiopia.

Acknowledgments: The author is thankful to Injibara University.

Conflicts of Interest: The authors declare no conflict of interest 


\section{Acknowledgments:}

This work has been financed from Injibara University under the title: determination of Aflatoxin in raw cow's milk by using HPLC-FLD, in Injibara town, Awi Zone, Amhara, Ethiopia, and the authors would like to thank both the university fund money and laboratory personnel of Ethiopian confirmative assessment enterprise agency for kind fund and technical assistance. 


\section{References}

1. Polovinski Horvatović, M., Glamočić, D., Jajić, I., Krstović, S., Guljaš, D. and Gjorgjievski, S., 2016. Aflatoxin M1 in raw milk in the region of Vojvodina. Mljekarstvo: časopis za unaprjeđenje proizvodnje i prerade mlijeka, 66(3), pp.239-245.

2. Panahi, P., Kasaee, S., Mokhtari, A., Sharifi, A. and Jangjou, A., 2011. Assessment of aflatoxin M1 contamination in raw milk by ELISA in Urmia, Iran. American-Eurasian Journal of Toxicological Sciences, 3(4), pp.231-233.

3. Guetouache, M., Guessas, B. and Medjekal, S., 2014. Composition and nutritional value of raw milk. Journal Issues ISSN, 2350, p.1588.

4. Abera, A., 2016. Review on the Impact of Aflatoxin in Dairy Industry: Occurrence and Control the Case of Ethiopia.

5. Bakırdere, S., Bora, S., Bakırdere, E.G., Aydın, F., Arslan, Y., Komesli, O.T., Aydın, I. and Y1ldirım, E., 2012. Aflatoxin species: their health effects and determination methods in different foodstuffs. Central European Journal of Chemistry, 10(3), pp.675-685.

6. Guchi, E., 2015. Aflatoxin contamination in groundnut (Arachis hypogaea L.) caused by Aspergillus species in Ethiopia. Journal of Applied \& Environmental Microbiology, 3(1), pp.11-19.

7. Darsanaki, R.K., Mohammadi, M., Kolavani, M.H., Issazadeh, K. and Aliabadi, M.A., 2013. Determination of aflatoxin M1 levels in raw milk samples in Gilan, Iran. Adv Stud Biol, 5(4), pp.151-6.

8. Bedi, P.S., and Khare, R., 2012. Aflatoxins: occurrence and their effects-A review. Curr. Trends Biotech. Chem. Res, 2(1), pp.15-25.

9. Yitbarek, M.B., and Tamir, B., 2014. Mycotoxins and/or aflatoxins in milk and milk products. American Scientific Research Journal for Engineering, Technology, and Sciences (ASRJETS), 4(1), pp.1-32.

10. Ayalew, D., Tesfaye, K., Mamo, G., Yitaferu, B. and Bayu, W., 2012. Variability of rainfall and its current trend in Amhara region, Ethiopia. African Journal of Agricultural Research, 7(10), pp.1475-1486. http://dx.doi.org/10.5897/AJAR11.698

11. Chauhan, A., Mittu, B., and Chauhan, P., 2015. Analytical method development and validation: a concise review. Journal of Analytical \& Bioanalytical Techniques, 6(1), p.1. 
12. Prichard, E. and Barwick, V., (2007). Quality Assurance in Analytical Chemistry. John Wiley and Sons: New York, pp 86-88.

13. Dawit, G., Barbara, S., Azage, T., Jean, H., Delia, G., 2015. Aflatoxin analysis of dairy feeds in the Greater Addis Ababa milk shed, Ethiopia.

14. Ayhan, F., Sinan, I., and Fusun, T., 2010. Survey of the occurrence of aflatoxin M1 in cheeses produced by dairy ewe's milk in Urfa city, Turke. Ankara üniversitesi veterinary fakültesi dergisi, 57(3), pp.197-199.

15. Yohannes B., Wondossen A., and Anteneh G., 2018. Analysis to Ascertain the Determination for Aflatoxin Contamination of Milk and Feeds from Gurage Zone, Ethiopia. International Journal of Agricultural Research, 13, pp.1-11.

16. Jawaid, S., Talpur, F.N., Nizamani, S.M., and Afridi, H.I., 2015. Contamination profile of aflatoxin M1 residues in the milk supply chain of Sindh, Pakistan. Toxicology reports, 2 , pp.1418-1422.

17. Lunden, H., 2015. What is milk? Aflatoxin and antibiotic residues in cow's milk in Assam, North East India. MSc Thesis, Swedish University of Agricultural Sciences, Uppsala, Sweden.

18. Amer, A.A. and Ibrahim, M.E., 2010. Determination of aflatoxin M1 in raw milk and traditional cheeses retailed in Egyptian markets. Journal of Toxicology and Environmental Health Sciences, 2(4), pp.50-52.

19. Oyebanji, A.O. and Efiuvwevwere, B.J.O., 1999. Growth of spoilage mould and aflatoxin B1 production in naturally contaminated or artificially inoculated maize as influenced by moisture content under ambient tropical conditions. International biodeterioration \& biodegradation, 44(4), pp.209-217.

20. Idris, Y.M., Mariod, A.A., Elnour, I.A. and Mohamed, A.A., 2010. Determination of aflatoxin levels in Sudanese edible oils. Food and Chemical Toxicology, 48(8-9), pp.2539-2541.

21. Iqbal, S.Z., Asi, M.R. and Ariño, A., 2011. Aflatoxin M1 contamination in cow and buffalo milk samples from the Northwest Frontier Province (NWFP) and Punjab provinces of Pakistan. Food Additives and Contaminants: Part B, 4(4), pp.282-288. 


\section{Appendix A: Chromatogram of Spiked samples}

\section{Spiked 23}

Spiked 25

Spiked 28

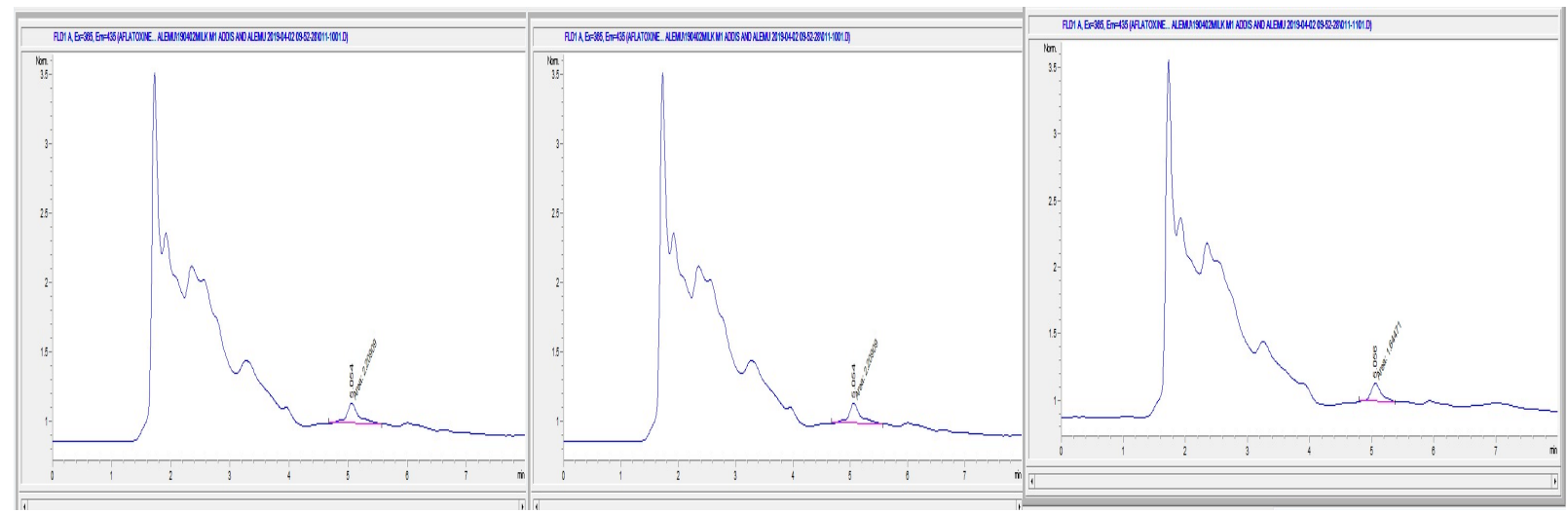

\section{Appendix B: Chromatogram of standard AFM1}

$0.5 \mu \mathrm{g} / \mathrm{L}$ Aflatoxin M1

$2 \mu \mathrm{g} / \mathrm{L}$ Aflatoxin M1

$4 \mu \mathrm{g} / \mathrm{L}$ Aflatoxin M1

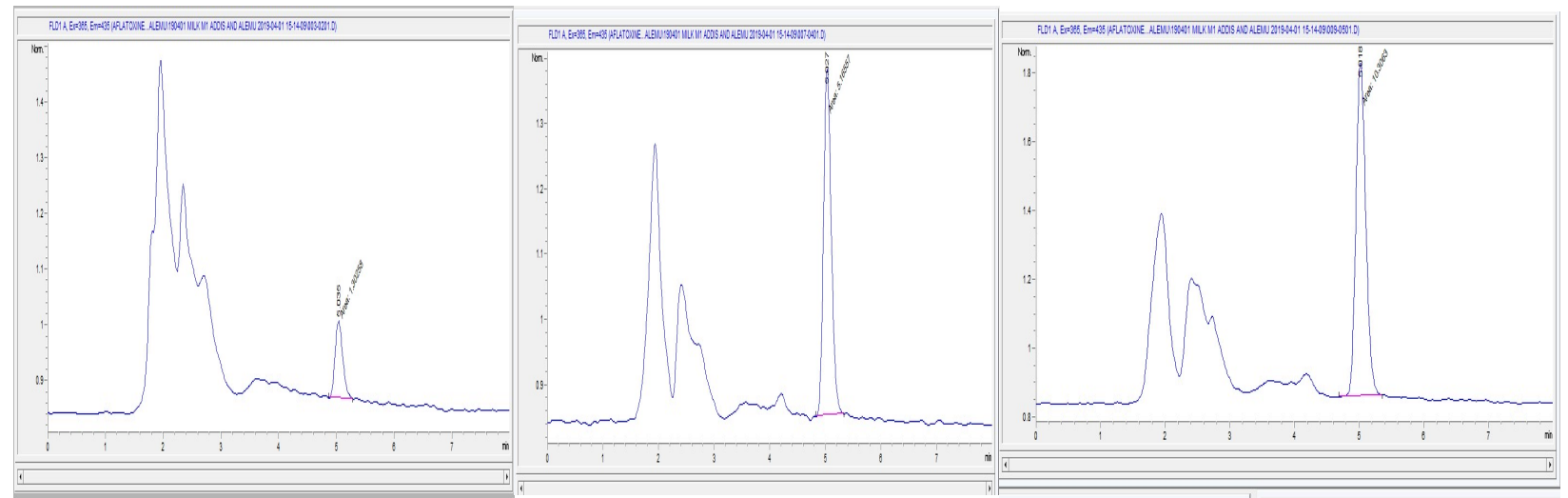

Sample 23 overlaid with $0.5 \mu \mathrm{g} / \mathrm{L}$ M1 standard Sample 29 overlaid with $0.5 \mu \mathrm{g} / \mathrm{L}$ M1 standard 


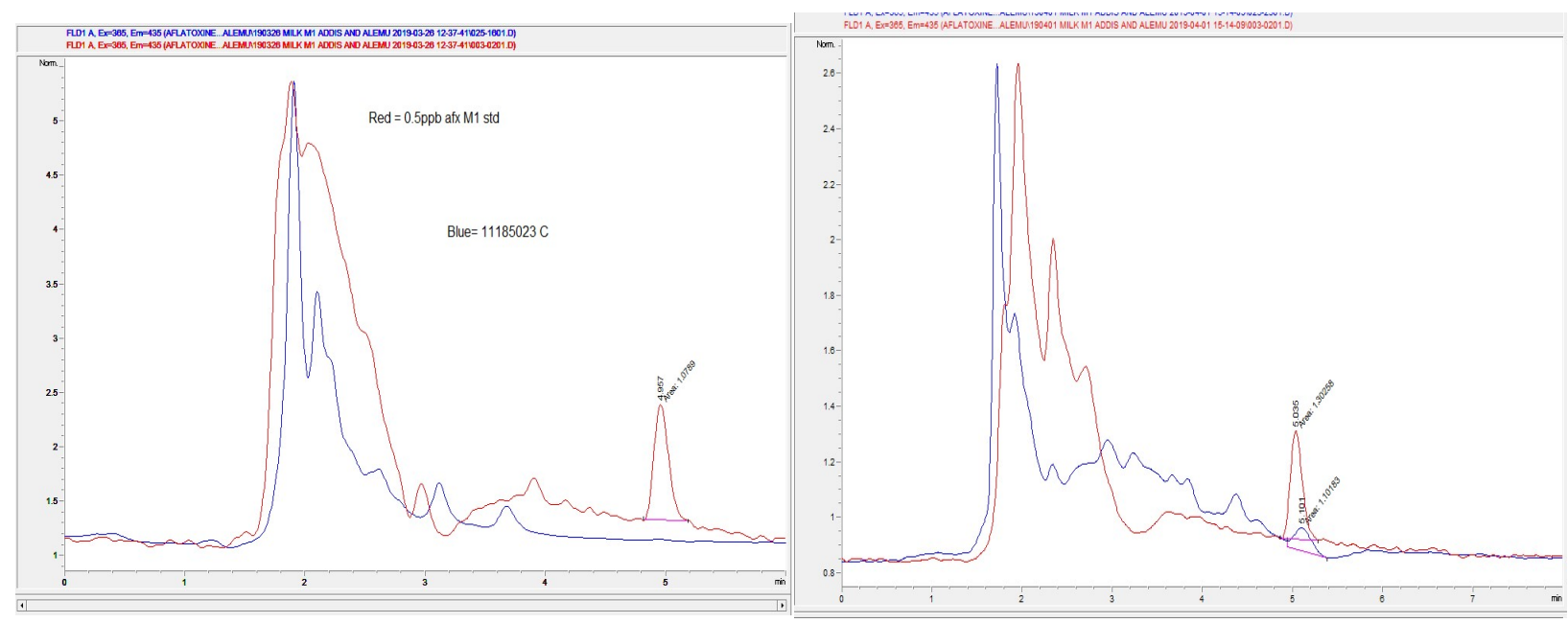

